\title{
Research Note \\ Preveraison Water Deficit Accelerates Berry Color Change in Merlot Grapevines
}

\author{
Jose C. Herrera ${ }^{1 *}$ and Simone D. Castellarin ${ }^{2}$
}

\begin{abstract}
In red varieties, berry color change from green to red is one of the first events associated with ripening and is often used as an indicator of veraison by viticulturists. Water deficit can accelerate ripening and increase pigment accumulation in the berry skin. The impact of water deficit on the timing and progression of berry color change in the vineyard has been largely overlooked. Here we present three years of observations (2011 to 2013) on the progression of color change in Merlot vines subjected to water deficit (WD) or irrigation (C) regimes. Water deficit did not affect the date at which berries started changing color in 2011 and 2012, but pigmentation began three days earlier in WD than in $\mathrm{C}$ vines in 2013. Water deficit accelerated pigmentation in all three years and WD berries completed color change five days earlier than $\mathrm{C}$ berries on average.
\end{abstract}

Key words: anthocyanins, berry ripening, deficit irrigation, Vitis vinifera L.

In grapevine, berry development follows a double sigmoid growth curve consisting of two growth phases (Stages I and III) separated by a lag phase (Stage II) during which expansion slows (Coombe 1992). The onset of berry ripening, or veraison, is associated with the transition from Stage II to Stage III (Coombe 1992) and is normally observed $\sim 8$ to 10 weeks after blooming. At this stage, significant physicochemical changes occurring in the berry include softening, the resumption of growth, decreased organic acid concentrations, and accumulation of sugars and anthocyanins (in red varieties). As a first noticeable sign of ripening, veraison is a major phenological stage. The date of veraison is usually recorded in commercial vineyards and used as a phenological reference for application of several viticultural practices and to predict harvest. For any given vineyard, the date of veraison can vary significantly among years, among vines, among clusters on a single vine, and among berries within a cluster. Differences in the timing of flowering and fertilization have been suggested as factors causing this asynchrony

${ }^{1}$ Dep. of Agricultural, Food, Environmental, and Animal Sciences, University of Udine, Via delle Scienze 206, 33100 Udine, Italy; and ${ }^{2}$ Wine Research Centre, the University of British Columbia, 2205 East Mall, Vancouver BC V6T 1Z4, Canada.

*Corresponding author (jc.herrera@uniud.it; tel: +39 0432558631; fax: +39 0432558603)

Acknowledgments: This research was partially funded by EU Cross-Border Cooperation Programme Italy-Slovenia 2007-2013 (VISO) and the FriuliVenezia-Giulia Region (GiSVI). The authors thank Isabella Paladino and Chiara Di Gravio for valuable support in the field measurements and statistical analyses, respectively.

Supplemental data is freely available with the online version of this article at www.ajevonline.org.

Manuscript submitted Aug 2015, revised Dec 2015, accepted Jan 2016

Copyright (C) 2016 by the American Society for Enology and Viticulture. All rights reserved.

doi: 10.5344/ajev.2016.15083
(Coombe 1992). The seed weight-to-berry weight ratio also affects the timing of ripening initiation: berries with a higher seed weight-to-berry weight ratio start ripening later than berries with a lower ratio (Gouthu and Deluc 2015).

As a result of the berry-to-berry variability, the veraison date in a vineyard is often defined as the date at which $50 \%$ of the berries exhibit ripening signs such as softening and translucent color in white grape varieties or red pigmentation in red varieties. In red varieties, the color change occurs when the berry is at 9 or 10 Brix (Keller 2010), and is a reliable indicator of the shift in berry metabolism observed at the onset of ripening. The change in berry pigmentation at veraison can be from green to pink, red, purple, or blue hues according to the identities and concentrations of anthocyanins synthesized (Castellarin and Di Gaspero 2007). In this manuscript, any berry that has changed color from green to pink, red, purple, or blue is referred to as a red berry, and berry color change from green to red is defined as the pigmentation process.

The interval between bloom and veraison is strongly determined by the genetic background of the given variety (Costantini et al. 2008). Reducing the bloom-to-veraison interval through viticultural practices could accelerate the entrance of the berries into the ripening phase, giving the berries more time to ripen. This would be particularly valuable in viticultural areas characterized by a short growing season or a cool climate. Deficit irrigation treatments imposed from early stages of fruit development can accelerate sugar accumulation, advance the harvest date (Shellie 2006, Castellarin et al. 2007), and promote the biosynthesis and concentration of anthocyanins in the berry skin (Castellarin et al. 2007, Ollé et al. 2011). Water deficit may induce an earlier beginning and an earlier end of color change in berries of vines subjected to water deficit from fruit set to veraison (Hardie and Considine 1976, Castellarin et al. 2007), hence favoring a longer ripening period. Here we present three years of observations (2011 to 2013) on the progression of berry pigmentation in a 
Merlot vineyard under water deficit (WD) and well-watered (C) conditions.

\section{Materials and Methods}

The experiment was conducted in 2011, 2012, and 2013 at the University of Udine experimental station "A. Servadei" (lat. $46^{\circ} 02^{\prime} \mathrm{N}$; long. $13^{\circ} 13^{\prime} \mathrm{E}$; elevation $88 \mathrm{~m}$ asl), in an 18 -year-old Merlot vineyard grafted onto SO4 rootstock. The experimental site and design has been described in detail (Herrera et al. 2015). Briefly, to maintain the vines under a fully controlled water regime, four $85 \mathrm{~m}$-long rows were covered with an ethylene-vinyl-acetate film using a five $\mathrm{m}$ high, open-side tunnel structure. Only the central rows were included in the trial. Water was supplied by a subsurface drip irrigation system and, with the exception of irrigation scheduling, vines were managed according to standard commercial practice that included interrow cover crop maintenance, weed removal, pesticide application, and nutrient management. An automated weather station located $100 \mathrm{~m}$ from the experimental site recorded maximum, minimum, and average daily temperatures, precipitation, relative humidity, wind speed, and radiation.

Two water regimes were established from 31, 24, and 25 days after anthesis (DAA) in 2011, 2012, and 2013, respectively: i) Well-watered control (C), in which vines were irrigated weekly at $100 \% \mathrm{ET}_{\mathrm{c}}$ to maintain midday stem water potential $\left(\Psi_{\text {stem }}\right)$ between -0.4 and $-0.6 \mathrm{MPa}$; and ii) Water deficit (WD), in which irrigation was withheld from 25 to 31 DAA and, when $\Psi_{\text {stem }}$ was below $-1.4 \mathrm{MPa}$, irrigation was managed to maintain $\Psi_{\text {stem }}$ between -1.2 and $-1.4 \mathrm{MPa}$ until harvest. Each treatment was replicated four times in experimental plots of 10 vines each in a completely randomized design. Vine water status was estimated weekly using midday measurements of $\Psi_{\text {stem }}$ as described (Herrera et al. 2015).

Monitoring berry pigmentation. A tagging method was used to monitor berry pigmentation in the vineyard. In each experimental plot, 10 clusters were randomly selected, tagged, and numbered at $40 \mathrm{DAA}$ when all the berries were still green. Within each cluster, five berries were randomly selected, tagged, and numbered with progressive numbers; thus, 40 clusters and 200 berries were considered for each treatment. These tagged berries were observed every two days from the start of berry color change ( $\sim 50$ to 55 DAA) until the day all tagged berries on all tagged clusters were red. At the first observed change in color from green to pink, red, purple, or blue, the berry was categorized as red. The date when a given berry was classified as red was recorded as the veraison date for that berry. In parallel to this methodology, we added a visual estimate of the percentage of berries within each tagged cluster that had changed color at each observation date, irrespective of the status of the five tagged berries. These visual estimates were then compared with the data on the tagged berries.

Statistical analyses. The effect of water deficit on the speed of the pigmentation process in the population of berries was assessed using a survival analysis technique (Rich et al. 2010) performed with JMP software (JMP 7.0, SAS Institute,
Inc.). Survival analysis is commonly used in medicine and microbiology to study follow-up times from a defined starting point to the occurrence of a given event; for example, the time from the beginning to the end of a remission period or the time from the diagnosis of a disease to death. The survival function $\mathrm{S}(t)$ is defined as the probability of surviving at least to time $t$. In our case, "surviving" was defined as a berry remaining green, as the event of interest was berry color change from green to red. The graph of $\mathrm{S}(t)$ against $t$ is called the survival curve. The Kaplan-Meier method can estimate this curve from the observed survival times without assuming the existence of an underlying probability distribution. We used this method to calculate the survival function in both $\mathrm{C}$ and WD treatments and tested for significant differences using the log-rank test at $p<0.05$ (Rich et al. 2010).

The chi-square test $(p<0.05)$ was used to assess significant differences between the proportions of green and red berries in $\mathrm{C}$ and WD clusters at each observation date.

\section{Results}

Climate, phenology, and vine water status. Seasonal climatic conditions were different among the three years of experiments (Supplemental Table 1). Generally, the summers in 2012 and 2013 were warmer than in 2011 and the historical mean (1991 to 2013). However, monthly mean air temperatures during August (when veraison occurred) were warmer than the 1991 to 2013 average in all three years and were similar among years. Growing degree day (GDD) accumulations from 1 April to 30 Sept were similar for 2011 and 2012 (1947 and 1935 GDD, respectively), and higher than in 2013 (1785 GDD) and the historical average (1721 GDD).

Budbreak occurred on 10 April in 2011 and 2012, and on 17 April in 2013 (Table 1). Anthesis occurred earlier in 2011 (22 May) than in 2012 and 2013 (3 June and 7 June, respectively). Veraison (50\% of red berries in the vineyard) occurred at 70, 60, and 65 DAA in 2011, 2012, and 2013, respectively. Grapes from $\mathrm{C}$ and WD were harvested on 14 Sept (115 DAA), 18 Sept (107 DAA), and 25 Sept (110 DAA) in 2011, 2012, and 2013, respectively.

The deficit irrigation treatment significantly reduced the $\Psi_{\text {stem }}$ of grapevines (Figure 1). In all three years, the $\Psi_{\text {stem }}$ of $\mathrm{C}$ vines remained consistently higher than $-0.60 \mathrm{MPa}$ throughout the season, while it decreased progressively in WD vines after irrigation was withheld. WD $\Psi_{\text {stem }}$ was below $\mathrm{C} \Psi_{\text {stem }}$ from 51, 40, and 38 DAA in 2011, 2012, and 2013, respectively; at these stages, WD $\Psi_{\text {stem }}$ was $-0.70,-0.95$, and $-0.66 \mathrm{MPa}$. Differences were mainly associated with the time

Table 1 Dates of the major phenological stages of vines in the experimental vineyard in 2011, 2012, and 2013.

\begin{tabular}{lccc}
\hline Phenology stage & $\mathbf{2 0 1 1}$ & $\mathbf{2 0 1 2}$ & $\mathbf{2 0 1 3}$ \\
\hline Budbreak & $99^{\mathrm{a}}$ & 100 & 106 \\
Anthesis $(50 \%$ capfall) & 141 & 154 & 157 \\
${\text { Veraison }(50 \%)^{\mathrm{b}}}^{\text {Harvest }}$ & 210 & 214 & 220 \\
\hline
\end{tabular}

aDates are given as day of the year.

${ }^{b}$ Veraison stage is that of the well-watered control (C) treatment. 
at which irrigation treatments were applied as in 2011, the treatments were imposed 31 DAA, a week later than in 2012 (24 DAA) and 2013 (25 DAA).

Impact of water deficit on berry pigmentation. The first colored berries in $\mathrm{C}$ vines were observed at 64,55 , and 59

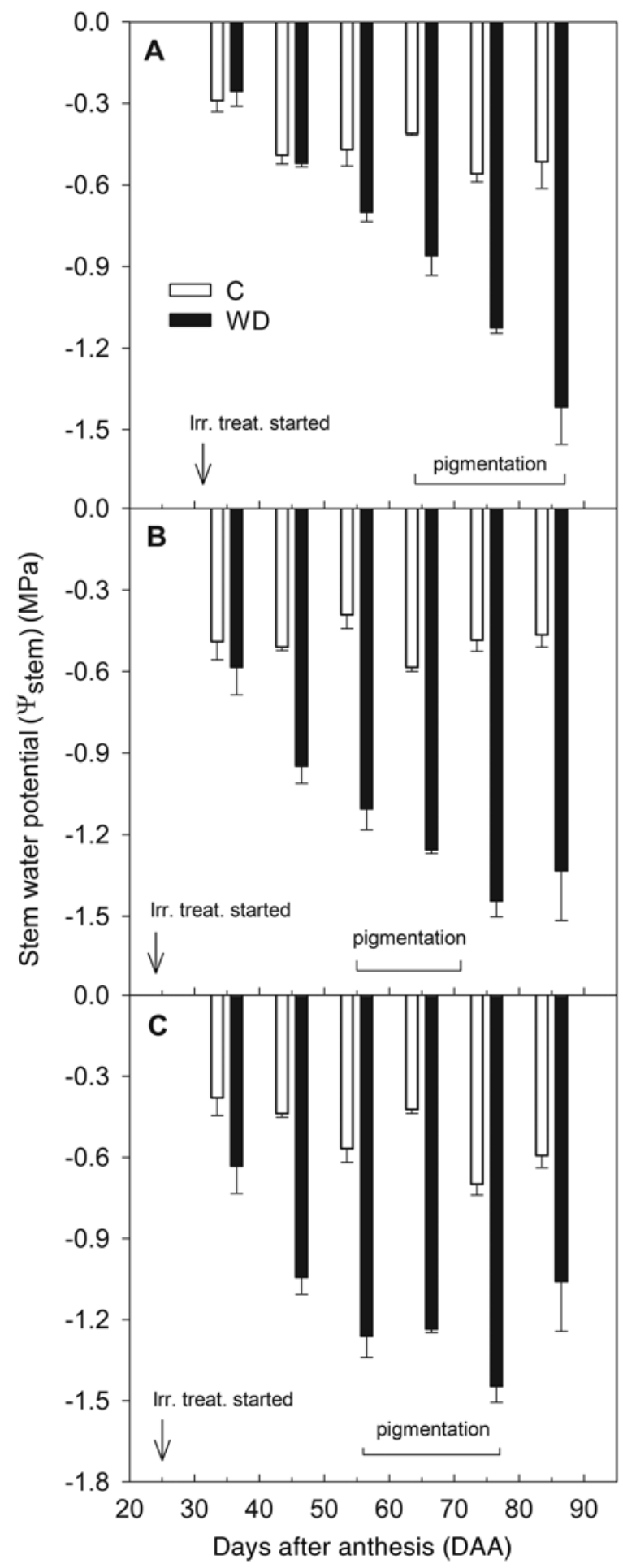

Figure 1 Midday stem water potential $\left(\Psi_{\text {stem }}, \mathrm{MPa}\right)$ of irrigated $(\mathrm{C})$ and water deficit (WD) Merlot grapevines in (A) 2011, (B) 2012, and (C) 2013. $\Psi_{\text {stem }}$ values are means and standard errors within the given time period (DAA). Arrows indicate the date of imposed irrigation treatments. Pigmentation period indicates the time lapse between the first colored berry observed and $100 \%$ red berries, irrespective of treatment.
DAA, and all the berries had changed color by 87,71 , and 77 DAA in 2011, 2012, and 2013, respectively (Figure 2). In contrast, the first colored berries in WD vines were observed at 65,55 , and 56 DAA in 2011, 2012, and 2013, respectively, and all berries had changed color by 81 DAA in 2011 and by 68 DAA in 2012 and 2013. Hence, in two out of three years, there was no significant difference between irrigation treatments in the date of first color change. In 2013, the first color occurred three days earlier in WD than in C. Each year, the rate of berry color change was greater in vines under WD than C irrigation treatment. WD berries completed the pigmentation process seven, three, and six days before $\mathrm{C}$ berries in 2011, 2012, and 2013, respectively (Figure 1). The survival analysis $(p<0.05)$ confirmed that this increase in pigmentation speed was significant in all three years (Supplemental Figure 1).

The same phenomenon described above was observed when pigmentation was assessed by visually estimating the percentage of red berries on the entire clusters (Supplemental Figure 2). A significant linear regression $(p<0.001)$ was observed between the percentages of red berries among the five berries that were tagged per cluster and the percentages estimated by observing the entire cluster (Figure 3 ).

\section{Discussion}

In the three years of this study, C and WD vines had significantly different degrees of water deficit prior to veraison, and preveraison water deficit accelerated the rate of berry color change in the vineyard. When preveraison water deficit was milder $\left(\Psi_{\text {stem }}=-0.7 \mathrm{MPa}\right.$ from 40 to $50 \mathrm{DAA}$ in 2011), significant differences in the percentage of red berries between the irrigation treatments occurred later in development than when the deficit was more severe ( $\Psi_{\text {stem }}=-0.95$ and -1.04 MPa from 40 to 50 DAA in 2012 and 2013, respectively). On the other hand, in 2013, when the preveraison water deficit was more severe than in the other two seasons, pigmentation started earlier in WD than in $\mathrm{C}$ vines and differences in the percentage of red berries between irrigation treatments were significant throughout pigmentation. The earlier achievement of red berry pigmentation in Merlot vines subjected to water deficit was due to a faster transition from $100 \%$ green to $100 \%$ red berries, rather than to an earlier onset of berry pigmentation in the vineyard. In an experiment with potted Cabernet franc vines subjected to several irrigation treatments, berries of vines subjected to preveraison water deficit from 44 DAA to 76 DAA began to change color five days earlier and completed the color transition in a shorter period than berries of irrigated vines (control) and berries of vines subjected to early (from 22 DAA to 44 DAA) preveraison water deficit followed by restored irrigation prior to veraison (Hardie and Considine 1976). The authors hypothesized that a high sugar concentration induced by temporary shriveling might explain the early coloration of berries subjected to water deficit; however, in our study, no shriveling was observed in WD berries. Water deficit imposed from fruit set until the end of veraison (77 DAA) induced an earlier beginning and end of color change in Cabernet Sauvignon berries (Castellarin et al. 2007). Both of these studies were based on few observations 

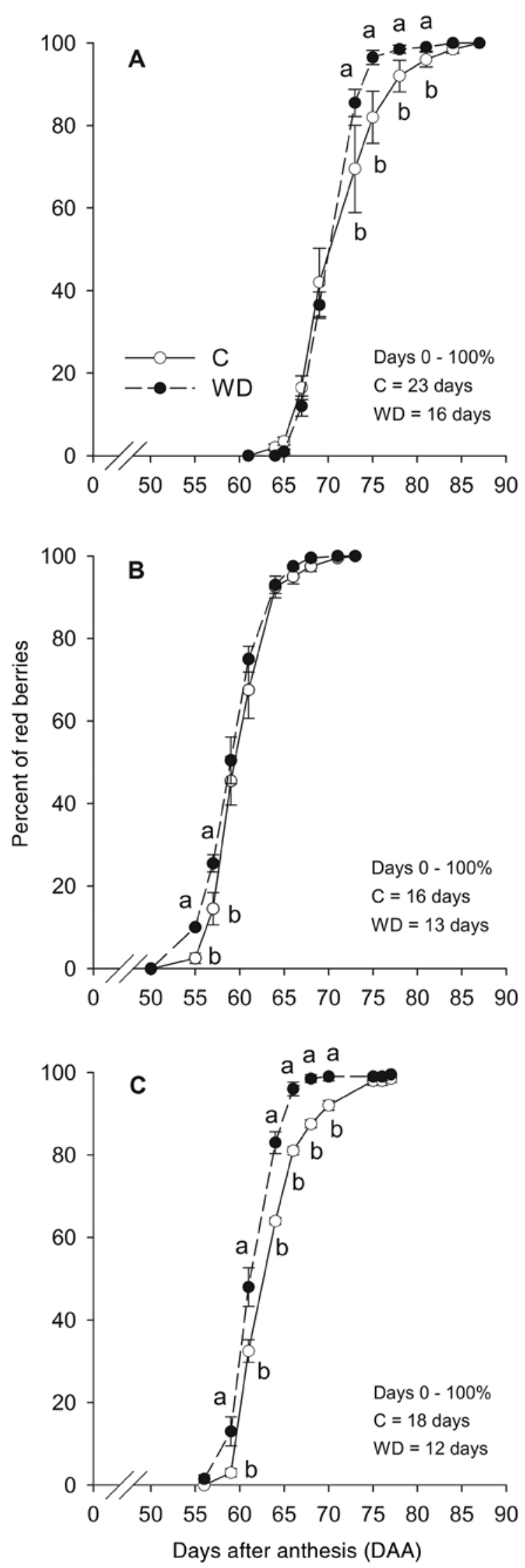

Figure 2 Effect of water deficit on the progression of berry pigmentation (\% red berries) assessed by observing tagged berries in (A) 2011, (B) 2012, and (C) 2013. Each point is the mean of four plots (50 berries each) at a given observation date. Bars represent the standard error $(n=4)$. within a single experimental season and reported no detailed data on the progression of color change, but anticipation of the beginning of color change appeared to be the major driver of the earlier completion of the berry pigmentation. In this study, Merlot vines subjected to water deficit did not begin the pigmentation process before irrigated vines in two out of three years. Interestingly, pigmentation started three days earlier in WD than in $\mathrm{C}$ vines in the season when water deficit was most severe before and at veraison, suggesting that the severity of water deficit may be critical for determining an earlier beginning of color change. Some authors reported that water deficit decouples anthocyanin from sugar accumulation during ripening (Castellarin et al. 2007, Sadras and Moran 2012, Herrera et al. 2015, Shellie 2015). While in this study, we did not couple the observations on color change with sugar analysis on the same berries, our results suggest that the uncoupling observed elsewhere may be related to the accelerated berry color change observed here and the faster pigmentation to enhanced anthocyanin biosynthesis from the onset of berry pigmentation. The hormone abscisic acid (ABA) may play a critical role in regulating the acceleration of berry pigmentation under water deficit. ABA concentration in the berry increases remarkably at veraison (Owen et al. 2009), and several studies indicated that ABA stimulates anthocyanin synthesis in grapevine by promoting expression of key biosynthetic genes (Jeong et al. 2004, Gambetta et al. 2010). Water deficit increases the ABA concentration in the berry (Hochberg et al. 2015) and the expression of ABA signaling genes at veraison, potentially involved in the regulation of ripening (Gambetta et al. 2010).

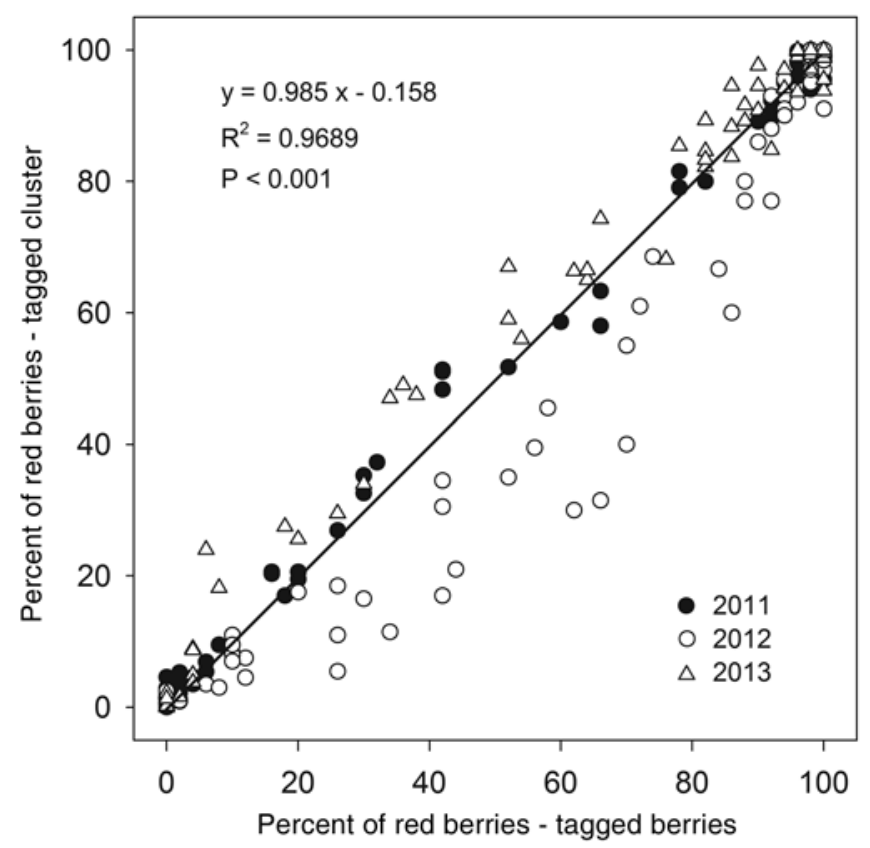

Figure 3 Relationship between the percentage of red berries among five tagged berries per cluster (200 berries per plot) and the percentage of red berries estimated by visually assessing pigmentation in tagged clusters (10 clusters per plot) at each sampling date in 2011, 2012, and 2013. Regression was calculated using the data from all three years together. 


\section{Conclusion}

Our study quantified the impact of water deficit on the timing of the onset of pigmentation in red grapes and showed that water deficit accelerates the transition of the berries from a green to a red hue. Water deficit hastened the beginning of fruit ripening, therefore prolonging the time from veraison to harvest as compared with well-watered conditions. This prolongation possibly contributed to determining the different fruit composition often observed at harvest under water deficit that can translate into improved sensory features of the derived wines.

\section{Literature Cited}

Castellarin SD and Di Gaspero G. 2007. Transcriptional control of anthocyanin biosynthetic genes in extreme phenotypes for berry pigmentation of naturally occurring grapevines. BMC Plant Biol 7:46.

Castellarin SD, Matthews MA, Di Gaspero G and Gambetta GA. 2007. Water deficits accelerate ripening and induce changes in gene expression regulating flavonoid biosynthesis in grape berries. Planta 227:101-112.

Coombe BG. 1992. Research on development and ripening of the grape berry. Am J Enol Vitic 43:101-110.

Costantini L, Battilana J, Lamaj F, Fanizza G and Grando MS. 2008. Berry and phenology-related traits in grapevine (Vitis vinifera L.): From quantitative trait loci to underlying genes. BMC Plant Biol 8:38.

Gambetta GA, Matthews MA, Shaghasi TH, McElrone AJ and Castellarin SD. 2010. Sugar and abscisic acid signaling orthologs are activated at the onset of ripening in grape. Planta 232:219-234.

Gouthu S and Deluc LG. 2015. Timing of ripening initiation in grape berries and its relationship to seed content and pericarp auxin levels. BMC Plant Biol 15:46.

Hardie WJ and Considine JA. 1976. Response of grapes to water-deficit stress in particular stages of development. Am J Enol Vitic 27:55-61.
Herrera JC, Bucchetti B, Sabbatini P, Zulini L, Vecchione A, Peterlunger E and Castellarin SD. 2015. Effect of water deficit and severe shoot trimming on the composition of Vitis vinifera L. Merlot grapes and wines. Aust J Grape Wine Res 21:254-265.

Hochberg U, Degu A, Cramer GR, Rachmilevitch S and Fait A. 2015. Cultivar specific metabolic changes in grapevines berry skins in relation to deficit irrigation and hydraulic behavior. Plant Physiol Biochem 88:42-52.

Jeong ST, Goto-Yamamoto N, Kobayashi S and Esaka M. 2004. Effects of plant hormones and shading on the accumulation of anthocyanins and the expression of anthocyanin biosynthetic genes in grape berry skins. Plant Sci 167:247-252.

Keller M. 2010. The Science of Grapevines: Anatomy and Physiology. Academic Press, New York

Ollé D, Guiraud JL, Souguet JM, Terrier N, Ageorges A, Cheynier V and Verries C. 2011. Effect of pre-and post-veraison water deficit on proanthocyanidin and anthocyanin accumulation during Shiraz berry development. Aust J Grape Wine Res 17:90-100.

Owen SJ, Lafond MD, Bowen P, Bogdanoff C, Usher K and Abrams SR. 2009. Profiles of abscisic acid and its catabolites in developing Merlot grape (Vitis vinifera) berries. Am J Enol Vitic 60:277-284.

Rich J, Neely JG, Paniello RC, Voelker CCJ, Nussenbaum B and Wang EW. 2010. A practical guide to understanding Kaplan-Meier curves. Otolaryngol Head Neck Surg 143:331-336.

Sadras VO and Moran MA. 2012. Elevated temperature decouples anthocyanins and sugars in berries of Shiraz and Cabernet Franc. Aust J Grape Wine Res 18:115-122.

Shellie KC. 2006. Vine and berry response of Merlot (Vitis vinifera L.) to differential water stress. Am J Enol Vitic 57:514-518.

Shellie KC. 2015. Foliar reflective film and water deficit increase anthocyanin to soluble solids ratio during berry ripening in Merlot. Am J Enol Vitic 66:348-356. 